\title{
Colon specific drug delivery of mesalamine using eudragit S100- coated chitosan microspheres for the treatment of ulcerative colitis
}

\author{
Seema Badhana ${ }^{1}$, Navneet Garud ${ }^{2}{ }^{*}$ Akanksha Garud ${ }^{1}$ \\ ${ }^{1}$ Department of Pharmaceutics, Institute of Professional Studies, College of Pharmacy, Gwalior-474001, India \\ ${ }^{2}$ School of Studies in Pharmaceutical Sciences, Jiwaji University, Gwalior, India
}

\begin{abstract}
The purpose of the present study was to prepare, characterize and evaluate the colon-targeted microspheres of mesalamine for the treatment and management of ulcerative colitis (UC). Microspheres were prepared by the ionicgelation emulsification method using tripolyphosphate (TPP) as cross linking agent. The microspheres were coated with Eudragit S-100 by the solvent evaporation technique to prevent drug release in the stomach. The prepared microspheres were evaluated for surface morphology, entrapment efficiency, drug loading, micromeritic properties and in-vitro drug release. The microspheres formed had rough surface as observed in scanning electron microscopy. The entrapment efficiency of microspheres ranged from $43.72 \%-82.27 \%$, drug loading from $20.28 \%-33.26 \%$. The size of the prepared microspheres ranged between $61.22-90.41 \mu \mathrm{m}$ which was found to increase with increase in polymer concentration. All values are statistically significant as $p<0.05$. Micromeritic properties showed good flow properties and packability of prepared microspheres. The drug release of mesalamine from microspheres was found to decrease as the polymer concentration increases. The release profile of mesalamine from eudragit-coated chitosan microspheres was found to be $\mathrm{pH}$ dependent. It was observed that Eudragit S100 coated chitosan microspheres gave no release in the simulated gastric fluid, negligible release in the simulated intestinal fluid and maximum release in the colonic environment. It was concluded from the study that Eudragit-coated chitosan microspheres were promising carriers for colon-targeted delivery of Mesalamine.
\end{abstract}

Key Words: Ionic-gelation emulsification method, cross-linking, drug release, delivery, particle size, $\mathrm{pH}$ dependent.

\section{INTRODUCTION}

Pharmaceutical invention and research are increasingly focusing on delivery systems which enhance desirable therapeutic objectives while minimizing side effects. Oral drug delivery system represents one of the frontier areas of drug delivery systems. Such a dosage form manages common concern which exists in area of cost-efficient treatment, patient compliance, optimum drug delivery and bioavailability (Kumar et al., 2012). The last two decades there has been a remarkable improvement in the field of novel drug delivery systems. Carrier technology offers an intelligent approach for drug delivery by coupling the drug to a carrier particle

\footnotetext{
*Corresponding Author:

Akanksha Garud, Associate Professor

Department of Pharmaceutics

Institute of Professional Studies, College of Pharmacy

Gwalior -474001, India

E-mail:akanksha.garud@gmail.com

Contact No.: +917512427805
}

such as microspheres, nanoparticles, liposomes, etc, which modulates the release and absorption characteristics of the drug (Dehghan et al., 2010).

Microspheres constitute an important part of this particulate drug delivery system by virtue of their small size and efficient carrier characteristics. However, the success of this novel drug delivery system is limited due to their short residence time at the site of absorption. It would therefore be advantageous to have means for providing an intimate contact of the drug delivery system with absorbing gastric mucosal membranes (Lohani and Gangwar, 2012). Microspheres are characteristically free powders consisting of proteins or synthetic polymers that are biodegradable in nature and ideally having a particle size less than $200 \mu \mathrm{m}$ (Alagusundaram et al., 2009). 
Colon specific drug delivery systems have gained increasing attention for the treatment of diseases such as Chrohn's disease, ulcerative colitis and irritable bowel syndrome (Patel et al., 2010). Ulcerative colitis is a type of inflammatory bowel disease (IBD) that affects the lining of the large intestine (colon) and rectum. Repeated swelling (inflammation) leads to thickening of the intestinal wall and rectum with scar tissue. Death of colon tissue or severe infection (sepsis) may occur with severe disease (Burger and Travis, 2011). Mesalamine (5ASA) is an anti-inflammatory drug used to treat crohn's disease and ulcerative colitis. Since Mesalamine (5-ASA) is largely absorbed from the upper intestine, selective delivery of drugs into the colon may be regarded as a better method of drug delivery with fewer side effects and a higher efficacy (Swapna et al., 2011).

In the present study, an attempt has been made to prepare mesalamine microspheres prepared by ionotropic gelation method using chitosan as polymer and sodium tripolyphosphate (TPP) as the cross-linking agent. Chitosan is a biodegradable natural polymer with great potential for pharmaceutical applications owing to its biocompatibility, non-toxicity and mucoadhesive properties. TPP is an extensively researched well established, charged, non-toxic, multivalent, anionic cross-linking agent with five bonding sites on the molecules.

\section{MATERIALS AND METHODS}

\section{Materials}

Mesalamine was obtained from Zydus Cadila, Ahmedabad, India. Chitosan was a gift sample from Central Institute of Fisheries Technology, Cochin. Eudragit S100 was obtained from Ranbaxy Laboratories Limited, New Delhi, India. TPP was purchased from Loba Chemicals. All other chemicals used in experiment were of analytical grade and used as such.

\section{Preparation of microspheres}

Cross linked chitosan microspheres were prepared using ionic-gelation emulsion method. Chitosan solution $(4 \% \mathrm{w} / \mathrm{v})$ was prepared in $5 \%$ aqueous acetic acid solution in which the drug was previously dissolved and dispersed in liquid paraffin containing span $80(1 \% \mathrm{w} / \mathrm{v})$ (Gawde and Agrawal,
2012). The dispersion was stirred using a specially fabricated stainless steel half-moon paddle stirrer and saturated aqueous solution of TPP $(1 \mathrm{ml}$ to 3 $\mathrm{ml})$, a cross-linking agent was added with continuous stirring. The stirring was continued for $4 \mathrm{~h}$, prepared microspheres were centrifuged, washed twice with hexane to remove oily phase from the solution and acetone and were then dried in vacuum desiccators for $48 \mathrm{hrs}$.

\section{Coating of chitosan microspheres}

Chitosan microspheres were coated with Eudragit S100 solvent evaporation method (Vasir et al., 2003). Chitosan microspheres $(50 \mathrm{mg})$ were dispersed in 10 $\mathrm{ml}$ of coating solution prepared by dissolution of $500 \mathrm{mg}$ of Eudragit S-100 in ethanol: acetone (2:1). This organic phase was then poured in $70 \mathrm{ml}$ of light liquid paraffin containing $1 \% \mathrm{w} / \mathrm{v}$ Span 80 . The system was maintained under agitation with speed of $1000 \mathrm{rpm}$ at room temperature for 3 hours to allow for the evaporation of solvent. Finally, the coated microspheres were filtered, washed with nhexane, and dried in desiccators (Jain et al., 2012).

\section{Identification by FT-IR spectrophotometer}

FTIR studies of mesalamine and formulation was carried out to find any possible interactions between the drug and the polymers during formulation (Garud et al., 2011a). FTIR spectra of drug and drugpolymer in formulation were obtained in $\mathrm{KBr}$ pellets using a Perkin Elmer model spectrum BX-FTIR spectrophotometer in the ranges, $4000-400 \mathrm{~cm}^{-1}$.

\section{Morphology and particle size}

Shape and surface morphology of microspheres were studied using Scanning Electron Microscope (SEM LEO 430, Leo Electron Microscopy Ltd., England). For determination of surface characteristics all the microspheres were coated uniformly with gold palladium by using sputter coater for 5 to 7 minutes, after fixing the sample in individual steps. All samples of microspheres were then randomly examined for surface morphology at different magnification ranges. Particle size of the microcapsules was evaluated using optical microscopy method (Lachman and Lieberman, 1991). Approximately 100 microspheres were counted for particle size determination using a calibrated optical microscope (Magnus MLX-DX). The experiments were performed in triplicate $(n=3)$. 


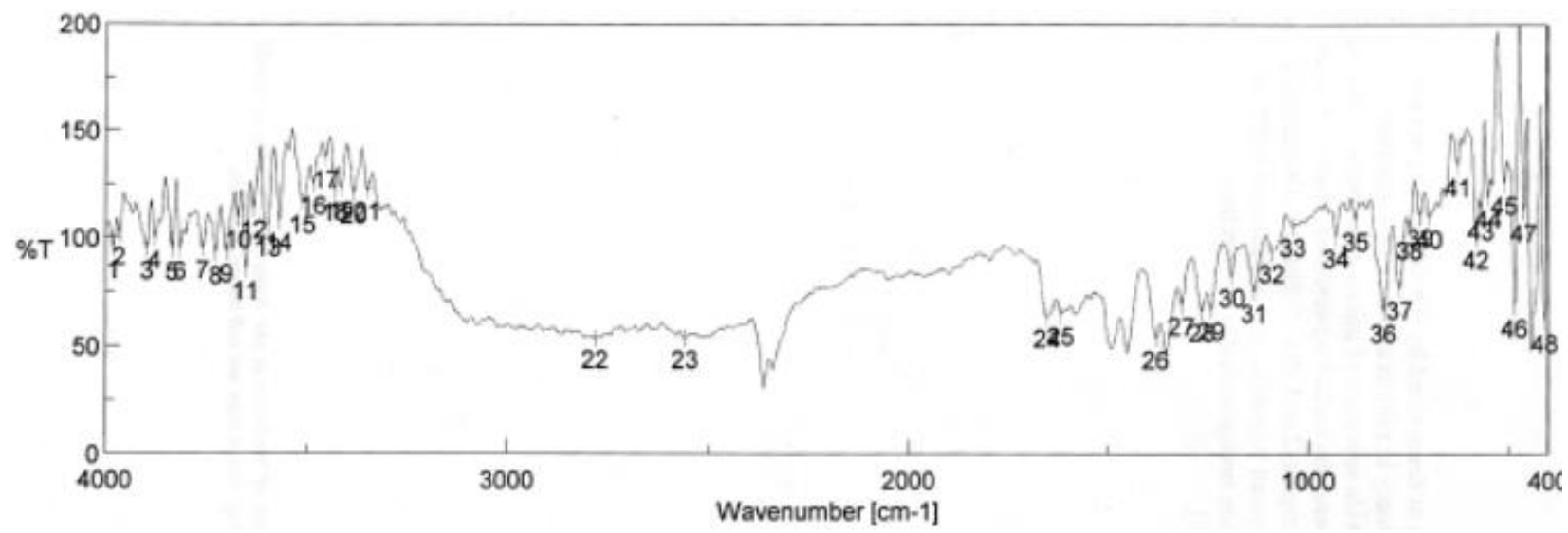

Figure 1: FT-IR Spectra of mesalamine.

\section{Micromeretic properties}

Accurately weighed microspheres were poured gently through a glass funnel into a graduated cylinder exactly to $10 \mathrm{ml}$ mark. Initial volume was noted. Bulk density and tapped density were noted using tapping method using $10 \mathrm{ml}$ measuring cylinder. Angle of repose $(\theta)$, Hausner's ratio $(\mathrm{H})$ and Carr's index ( $\% \mathrm{C}$ ) were calculated to study the flow properties of microspheres by using following formulas (Kancharla et al., 2011):

$\theta=\tan ^{-1} \frac{\mathrm{h}}{\mathrm{r}}$

where, $h$ is height and $r$ is radius of the pile, respectively.

$H=\frac{D t}{D b}$

$\% \mathrm{C}=\frac{D t-D b}{\mathrm{Dt}} \times 100$

where, $\mathrm{Dt}$ is tapped and $\mathrm{Db}$ is bulk density, respectively.

\section{Entrapment efficiency, drug loading and \% yield of microspheres}

$50 \mathrm{mg}$ of microspheres were dispersed in $10 \mathrm{ml}$ PBS $\mathrm{pH} 6.8$ for $10 \mathrm{~min}$ with occasional shaking. The suspension was then centrifuged for $5 \mathrm{~min}$ and the supernatant was kept aside. The sediment microspheres were then incubated for 48 hrs with PBS pH 6.8 and the drug concentration was determined spectrophotometrically by UV at $334 \mathrm{~nm}$ (Shimadzu Pharmspec UV-1700, Japan). The entrapment efficiency, drug loading and \% yield of microspheres $(n=3)$ were calculated by using following formulas (Garud and Garud, 2011b):
$\% E E=\frac{D c a l}{D t h} \times 100$

where, Dcal is the calculated drug content and Dth is the theoretical drug content, respectively.

$\% D L=\frac{W d}{W m} \times 100$

where, $\mathrm{Wd}$ and $\mathrm{Wm}$ represents weight of drug and weight of microspheres, respectively.

$\% Y=\frac{W m}{W t} \times 100$

where, Wt represents total expected weight of drug and polymer

\section{In-vitro release studies}

The drug release rate from the microspheres was studied in a medium of changing $\mathrm{pH}$ using the dissolution apparatus II at $37 \pm 0.5{ }^{\circ} \mathrm{C}$ with a rotation speed of $100 \mathrm{rpm}$. A weighed amount of mesalamine microspheres (equivalent to $50 \mathrm{mg}$ of drug) were added to dissolution medium $(350 \mathrm{ml}$ of $0.1 \mathrm{~N}$ $\mathrm{HCl}, \mathrm{pH}$ 1.2) for the first two hours. At the end of second hour, the $\mathrm{pH}$ of the dissolution medium was raised to 4.5 by the addition of $250 \mathrm{ml}$ solution composed of $3.75 \mathrm{~g}$ of $\mathrm{KH}_{2} \mathrm{PO}_{4}$ and $1.2 \mathrm{~g}$ of $\mathrm{NaOH}$. At the end of fourth hour $\mathrm{pH}$ was raised to 7.4 by adding $300 \mathrm{ml}$ of phosphate buffer concentrate (2.18 $\mathrm{g}$ of $\mathrm{KH}_{2} \mathrm{PO}_{4}$ and $1.46 \mathrm{~g}$ of $\mathrm{NaOH}$ in distilled water) (El-Bary et al., 2012). At predetermined time intervals, $5 \mathrm{ml}$ sample was withdrawn, passed through a $0.45 \mu \mathrm{m}$ membrane filter (Millipore). After appropriate dilutions, the concentration of drug in samples was analysed spectrophotometrically at

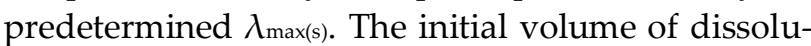
tion medium was maintained by adding $5 \mathrm{ml}$ of fresh dissolution medium after each withdrawal. 


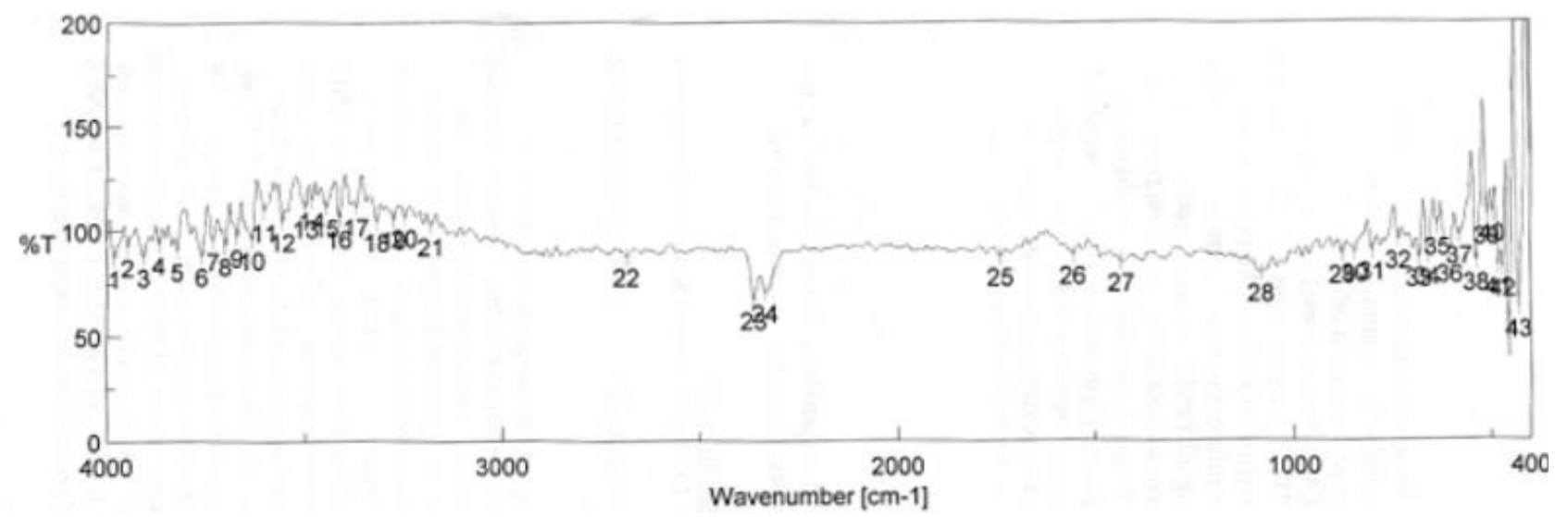

Figure 2: FT-IR Spectra of formulation.

Perfect sink conditions prevailed during the drug release studies.

\section{Statistical analysis}

The results were expressed in mean \pm S.D. One way ANOVA (Analysis of Variance) was performed for studying the statistical significance using Minitab 15 software. Values of $\mathrm{p}<0.05$ were considered to be significant.

\section{RESULTS AND DISCUSSION}

\section{Identification by FT-IR spectrophotometer}

FTIR studies of mesalamine and prepared formulation is shown in Figure 1 and 2. It is clear from the FTIR that the characteristic peaks of the drug are also present in the formulation depicting no incompatibility between the drug and polymers in the formulation.

\section{Morphology and particle size}

Visual examination of the SEM indicated that the

Table 1: Formulation composition of cross linked chitosan polymer.

\begin{tabular}{cccc}
\hline $\begin{array}{c}\text { S1. } \\
\text { No. }\end{array}$ & $\begin{array}{c}\text { Formulation } \\
\text { Code }\end{array}$ & Drug:Polymer & $\begin{array}{c}\text { Emulsifier concen- } \\
\text { tration }(\mathbf{m l})\end{array}$ \\
\hline 1 & M1 & $1: 1$ & 0.5 \\
2 & M2 & $1: 1$ & 1.0 \\
3 & M3 & $1: 1$ & 1.5 \\
4 & M4 & $1: 2$ & 0.5 \\
5 & M5 & $1: 2$ & 1.0 \\
6 & M6 & $1: 2$ & 1.5 \\
7 & M7 & $1: 3$ & 0.5 \\
8 & M8 & $1: 3$ & 1.0 \\
9 & M9 & $1: 3$ & 1.5 \\
\hline
\end{tabular}

microspheres of mesalamine were spherical with varied surface roughness (Figure 3). The particle size of microspheres ranged from 61.22-90.41 $\mu \mathrm{m}$ and were found to increase with increasing polymer content $(p<0.05)($ Table 2$)$. As the emulsifier concentration was increased from 0.5 to $1.5 \mathrm{ml}$, the particle size was found to increase in the prepared formulations $(\mathrm{p}<0.05)$.

\section{Micromeretic properties}

For the prepared formulations angle of repose $\left(11.65-16.29^{\circ}\right)$, Carr's index $(6.72-22.16 \%)$ and Hausner's ratio (1.10-1.29), confirmed good flow properties of the microspheres (Table 2).

Entrapment efficiency, drug loading and \% yield of microspheres

The microencapsulation efficiency for the different formulations was high (ranged from $43.72 \%$ to $82.27 \%$ ) and significantly increased with increasing chitosan content $(\mathrm{p}<0.05)$. Drug loading of microspheres was found to be ranging from $33.26 \pm 1.04$ to $20.28 \pm 0.96$ and it significantly decreased with increasing chitosan content $(p<0.05)$. The $\%$ yield of microsphere significantly increased with increasing chitosan content $(\mathrm{p}<0.05)$ and ranged from $63.99 \%$ to $84.94 \%$ for the prepared formulations (Figure 4 ). An increase in polymer concentration resulted in formation of larger microspheres entrapping greater amount of drug (Swapna et al., 2011).

\section{In vitro release studies}

In the in-vitro release studies, changing the $\mathrm{pH}$ conditions was attempted in lieu to mimic the GI conditions without enzymes. The $\mathrm{pH}$ condition used was $\mathrm{pH} 1.2$ for a period of $2 \mathrm{~h}$ (stomach), $\mathrm{pH} 4.5$ 
Table 2: Angle of repose, Carr's index, Hausner's ratio and particle size $(\mu \mathrm{m})$.

\begin{tabular}{ccccc}
\hline Formulation codes & $\begin{array}{c}\text { Angle of repose } \\
\text { Mean } \pm \text { SEM }\end{array}$ & $\begin{array}{c}\text { Carr's index } \\
\text { Mean } \pm \text { SEM }\end{array}$ & $\begin{array}{c}\text { Hausner's Ratio } \\
\text { Mean } \pm \text { SEM }\end{array}$ & $\begin{array}{c}\text { Particle Size }(\mu \mathrm{m}) \\
\text { Mean } \pm \text { SEM }\end{array}$ \\
\hline M1 & $16.29 \pm 0.68$ & $6.72 \pm 0.43$ & $1.29 \pm 0.30$ & $72.21 \pm 1.93$ \\
M2 & $16.16 \pm 0.65$ & $8.75 \pm 0.42$ & $1.10 \pm 0.28$ & $65.22 \pm 0.94$ \\
M3 & $15.52 \pm 0.63$ & $19.25 \pm 0.39$ & $1.23 \pm 0.31$ & $61.22 \pm 1.28$ \\
M4 & $13.65 \pm 0.54$ & $20.45 \pm 0.53$ & $1.22 \pm 0.27$ & $80.02 \pm 1.80$ \\
M5 & $13.85 \pm 0.59$ & $20.34 \pm 0.56$ & $1.25 \pm 0.27$ & $74.15 \pm 0.84$ \\
M6 & $14.34 \pm 0.53$ & $20.28 \pm 0.39$ & $1.31 \pm 0.26$ & $72.05 \pm 1.12$ \\
M7 & $11.65 \pm 0.61$ & $20.17 \pm 0.41$ & $1.34 \pm 0.30$ & $98.91 \pm 1.20$ \\
M8 & $11.98 \pm 0.59$ & $21.64 \pm 0.41$ & $1.27 \pm 0.29$ & $93.41 \pm 1.43$ \\
M9 & $12.34 \pm 0.52$ & $22.16 \pm 0.55$ & $1.28 \pm 0.27$ & $90.41 \pm 1.83$ \\
\hline
\end{tabular}

(duodenum) for $2 \mathrm{~h}$ followed by $\mathrm{pH} 7.4$ (distal ileum and colon) for the remaining duration of the study. A successful colon targeted drug delivery should have minimum drug release during its transit in the stomach and upper intestine to ensure maximum drug release in the colon (Chandran et al., 2009).

Eudragit S100 is an anionic copolymer of methacrylic acid and methyl methacrylate, the ratio of free carboxyl groups to the ester groups is approximately 1:2. It exhibits a dissolution threshold pH slightly above 7.2 (Sinha and Kumria, 2003). Due to the $\mathrm{pH}$-sensitive property of this polymer, it was selected to avoid the rapid dissolution of mesalamine during the initial transit of the microspheres through the gastric cavity and the upper small intestine.

The retardation in drug release was found to be significant with increasing polymer concentration

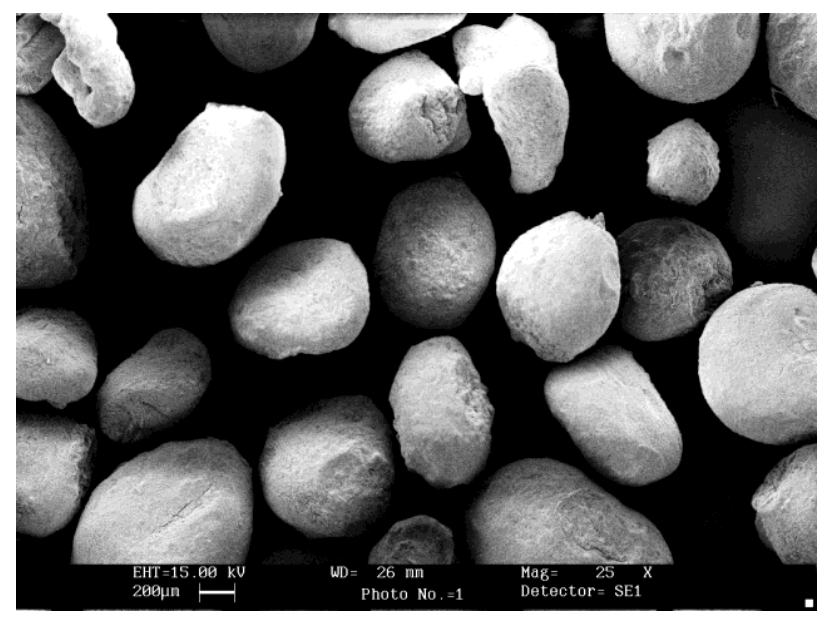

Figure 3: SEM of mesalamine-loaded chitosan microspheres. $(p<0.05)$. The increased density of polymer matrix at higher concentration resulted in an increased diffusion pathlength. This may decrease the overall drug release from the polymer matrix. Furthermore, smaller microspheres are formed at lower polymer concentration and have a larger surface area exposed to dissolution medium, giving rise to faster drug release (Srivastava et al., 2005). However, increase in emulsifier concentration in the formulations showed insignificant results in the drug release rate $(p>0.05)$. Eudragit coating of chitosan microspheres prevented the release of drug in stomach and targeted the delivery of drug to colon.

It was found that formulations with drug-polymer ratio of 1:1 (M1 to M3) released complete drug at 12 hours. A comparison of percentage release of drug from cross-linked chitosan microspheres vs time without coating is shown in Figure 5. A comparative $\%$ drug release of chitosan microspheres (M3, M6 and

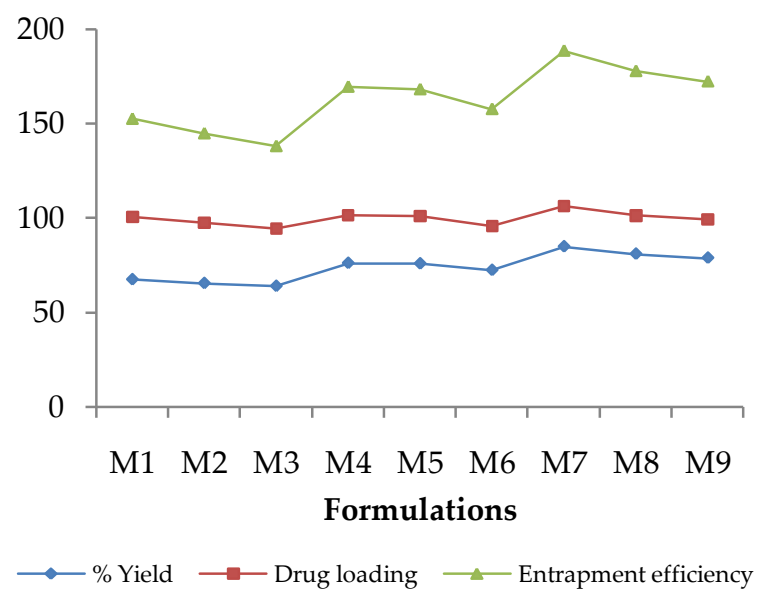

Figure 4: Percent yield, drug loading and entrapment efficiency of formulations. 


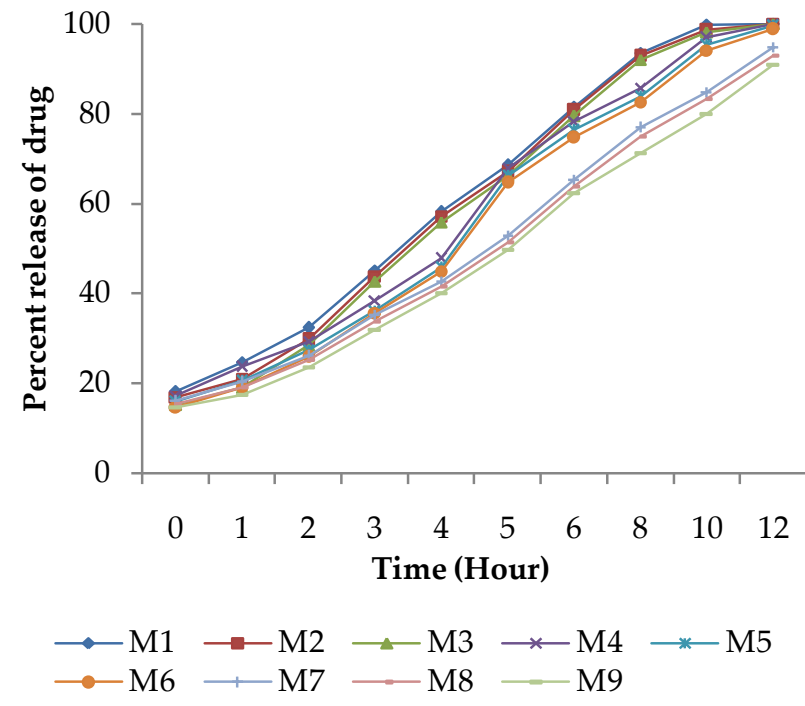

Figure 5: A comparison of percentage release of drug from cross-linked chitosan microspheres vs time (in hours) without coating.

M9) coated with Eudragit S-100 with drug-polymer ratio $1: 1,1: 2$ and $1: 3$, respectively at $1.5 \mathrm{ml}$ emulsifier concentration is depicted in Figure 6. It was observed that Eudragit S100 coated chitosan microspheres gave no release in the simulated gastric fluid, negligible release in the simulated intestinal fluid and maximum release in the colonic environment.

\section{CONCLUSION}

Mesalamine microspheres were prepared successfully by using the ionic-gelation emulsification method. Prepared microspheres showed good \% yield and drug loading. Encapsulation efficiency of microspheres was good for all formulations. The prepared microspheres with 1:3 ratio of drug-polymer coated with Eudragit S100 (M9) was found suitable for colonic release of mesalamine resisting drug release in gastric medium, minimizing release in the upper intestinal region and showing maximum release in the colonic region. Therefore, the developed formulation proves to be promising for the colon targeted drug delivery of mesalamine and thereby facilitating in the management of ulcerative colitis.

\section{ACKNOWLEDGEMENT}

Authors wish to thank Zydus Cadila, Ahmedabad, and Central Institute of Fisheries Technology, Cochin, India for providing the gift samples of mesalamine and chitosan, respectively.

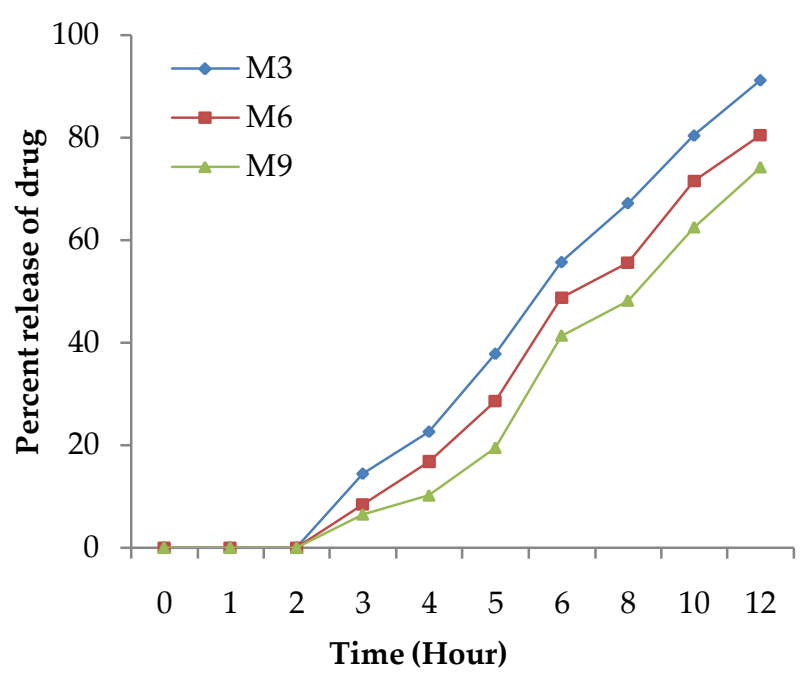

Figure 6: A comparative \% drug release of chitosan microspheres (M3, M6 and M9) coated with Eudragit S100 polymer.

\section{REFERENCES}

Alagusundaram M., Madhusudana C.C., Umasharkari K., Badrinath A.V., Lavanya C., Ramkanth S. (2009), Microspheres as a novel drug delivery system, International Journal of ChemTech Research. 1(3): 526-534.

Burger D., Travis S. (2011), Conventional medical management of inflammatory bowel disease, Gastroenterology. 140(6): 1827-1837. [DOI] PMid:21530749

Chandran S., Sanjay K.S., Ali Asghar L.F. (2009), Microspheres with $\mathrm{pH}$ modulated release: design and characterization of formulation variables for colonic delivery, Journal of Microencapsulation. 26(5): 420-431. [DOI] PMid:18821120

Dehghan S., Aboofazeli R., Avadi M., Khaksar R. (2010), Formulation optimization of nifedipine containing microspheres using factorial design, African Journal of Pharmacy and Pharmacology. 4(6): 346-354.

El-Bary A.A., Aboelwafa A.A., Al Sharabi I.M. (2012), Influence of some formulation variables on the optimization of $\mathrm{pH}$ dependent, colon targeted, sustained release mesalamine microspheres, AAPS PharmSciTech. 13(1): 7584. [DOI] PMid:22130789 PMCid:3299443

Garud N., Garud A., Jain N. (2011a), Formulation design and in-vitro evaluation of metformin microspheres using ionotropic gelation technique, Journal of Pharmacy Research. 4(7): 2103-2106.

Garud N., Garud A. (2011b), Preparation and in-vitro evaluation of metformin microspheres using non-aqueous solvent evaporation technique, Trop J Pharm Res. 13(4): 577-583.

Gawde P., Agrawal S. (2012), Design and characterization of Eudragit coated chitosan microspheres of Deflazacort for 
colon targeting, Journal of Pharmacy Research. 5(9): 48674870 .

Jain V., Gupta S., Pandey G.K., Dubey B.K., Jain P.K., Saluja M.S. (2012), Design and characterization of eudragit coated chitosan microspheres of mesalazine for irritable bowel disease, International Journal of Drug Discovery and Herbal Research. 2(1): 301-307.

Kancharla K., Basavaraj B.W., Bharath S., Deveswaran R., Madhavan V. (2011), Formulation and evaluation of intragastric floating multiparticulate system of Aceclofenac, Der Pharmacia Lettre. 3(2): 238-245.

Kumar K.P.S., Bhowmik D., Srivastava S., Paswan S., Dutta A.S. (2012), Sustained release drug delivery system potential, The Pharma Innovation. 1(2): 48-60.

Lohani A., Gangwar P.C. (2012), Mucoadhesive microspheres: A novel approach to increase gastroretention, Chronicles of Young Scientists. 3(2):121-128. [DOI]

Lachman L., Lieberman H.A., Kanig J.L. (1991), The Theory and Practice of Industrial Pharmacy, $2^{\text {nd }} E d$, Mumbai, India, Varghese Publishing House, 26-27.
Patel J.K., Patel R.P., Amin A.F., Patel M.M. (2005), Formulation and evaluation of mucoadhesive glipizide microspheres, AAPS Pharm Sci Tech. 6(1): E49-E55. [DOI] PMid:16353963 PMCid:2750411

Sinha V.R., Kumria R. (2003), Coating polymers for colon specific drug delivery: A comparative in vitro evaluation, Acta Pharm. 53(1): 41-47.

Srivastava A.K., Ridhurkar D.N., Wadhwa S. (2005), Floating microspheres of cimetidine: formulation, characterization and in vitro evaluation, Acta Pharm. 55(3): 277-285.

Swapna A., Mohd A.B., Wamorkar V., Swathimutyam P. (2011), Formulation and Evaluation of Mesalamine Microspheres for Colon Targeted Drug Delivery System, Journal of Pharmacy Research. 4(6): 1670-1672.

Vasir J.K., Tambwekar K., Garg S. (2003), Bioadhesive microsphere as a controlled drug delivery system, International journal of Pharmaceutics. 255(1-2): 13-32. [DOI] 